\title{
MOVIMENTOS NACIONAIS DE TRABALHADORES E CONEXÕES TRANSNACIONAIS: a evolução da arquite- tura das forças sociais do trabalho no neoliberalismo
}

\author{
Peter Evans*
}

\begin{abstract}
A era neoliberal minou os direitos dos trabalhadores e o poder das forças sociais do trabalho a nível nacional, mas foi caracterizada, também, como uma era do novo "transnacionalismo do movimento dos trabalhadores". Mudanças conjunturais a nível nacional foram fundamentais para aumentar a abertura às alianças transnacionais. Uma análise das campanhas evidencia isso. Avaliar as conexões entre movimentos nacionais de trabalhadores e a nova infraestrutura organizacional que emergiu no neoliberalismo é um ponto de partida necessário para construir teorias mais apuradas sobre as dinâmicas das contestações das forças sociais do trabalho ao capital global.
\end{abstract}

Palavras-chave: Trabalhadores. Sindicatos globais. Transnacionalismo. Sindicatos nacionais. Neoliberalismo.

\section{APRESENTAÇÃO' 1}

Evangelina Argueta e seus companheiros de militância do ramo de vestuário da Central General de los Trabajadores (CGT) hondurenha, ao forçar a gigante Russel Athletics, sediada nos Estados Unidos, a negociar um contrato em 2010, borraram a imagem convencional de vítimas passivas que caracterizava os trabalhadores de baixo salário. Segundo Argueta, "os líderes dos negócios em Hondu-

* University of California e Institute for International Studies da Brown University. Department of Sociology.

410 Barrows Hall Berkeley CA 94720. pevans@berkeley.edu

${ }^{1}$ Este artigo esteve tempo suficiente em preparação para acumular mais débitos do que posso expressar aqui, mas, seja-me permitido, ao menos, mencionar poucos dos que contribuíram. $\mathrm{O}$ artigo beneficiou-se fundamentalmente dos conhecimentos, ideias e sugestões de Mark Anner, Jessica Champagne, Eli Friedman, Kjeld Jakobsen, Carolyn Kazdin, Robert Lawson, and Jamie McCallum, que participaram do Workshop sobre 'New Strategies For Building Transnational Labor Solidarity', ocorrido na Brown University's Watson Institute for International Studies, no outono de 2012. Katy Fox-Hodess e Pablo Gaston brindaram a assistência editorial e acadêmica, ademais de suas próprias intuições. Publicado anteriormente em Peter Evans. National Labor Movements and Transnational Connections: Global Labor's Evolving Architecture Under Neoliberalism. Global Labor Journal, V. 5, N. 3, setembro de 2014. Tradução de Igor Peres Jerônimo. Revisão técnica de Marco Aurélio Santana e Ruy Braga. ras continuam perpetuando o mito de que em seu país - e particularmente na indústria da maquila ${ }^{2}$ - é impossível organizar, e que os sindicatos não serão tolerados em nenhuma circunstância. Por isso a vitória na Russel é tão importante. Prova que é possível organizar nas maquilas" (MSN, 2010).

A luta para organizar a Russel foi forjada por décadas de incansável trabalho em Honduras por militantes como Argueta, mas foi, também, uma vitória para a organização transnacional, possibilitada por uma rede transregional de Organizações Não-Governamentais voltadas ao mundo do trabalho e sindicatos que ligaram Honduras e os Estados Unidos. Casos como estes tornam evidente a possibilidade de construir uma atuação coletiva articulada das forças sociais do trabalho que ligue distintos territórios nacionais.

Embora Honduras pareça ser um lugar improvável para a observação de tendências da militância global, muitos considerariam o caso da Russel um exemplo do que é normalmente

2 [N.T. Maquila: local de trabalho baseado na combinação entre instrumentos de produção estrangeiros e força de trabalho local mal remunerada. O que é produzido nas maquilas geralmente é exportado]. 
chamado de "novo transnacionalismo do movimento dos trabalhadores”. Esforços para documentar e explicar a emergência de um "novo internacionalismo" começaram a proliferar na virada do milênio, como parte da onda generalizada de otimismo pós-Seattle (e.g. Mazur, 2000; Munck, 2002; Waterman, 2001). Em geral, as explicações enfatizaram as oportunidades e incentivos criados pela emergência de uma economia política mais globalizada. ${ }^{3}$

As condições gerais criadas pela globalização neoliberal são, certamente, decisivas para o destino do trabalhismo. Porém, os movimentos nacionais das forças sociais do trabalho continuam sendo os componentes mais importantes do movimento dos trabalhadores ao nível global, e a arquitetura geral da solidariedade das forças sociais do trabalho, igualmente global, depende de como as estratégias nacionais se orquestram. A possibilidade desta orquestração depende, por sua vez, das características dinâmicas dos campos políticos com os quais se depara o trabalhismo em cada contexto nacional. O movimento nacional dos trabalhadores pode aproveitar as diferenças entre os terrenos globais nos quais opera em vez de deixar a diferença minar a solidariedade? Como as mudanças nas conjunturas nacionais afetam a abertura do trabalhismo nacional às alianças transnacionais?

A literatura que aborda estas questões continua pouca desenvolvida. Com algumas notáveis exceções (por exemplo, Anner, 2011; McCallum, 2013), são poucos os estudos sobre o movimento dos trabalhadores ao nível global no neoliberalismo que esclareçam a evolução das interações entre movimentos dos trabalhadores em níveis nacionais. Análises históricas comparativas de amplitude (por exemplo, Silver, 2003) se dedicam mais a ressaltar as maneiras pelas quais o deslocamento geográfico da produção global afeta a mobilização em diferentes países do que as conexões entre os

${ }^{3}$ Para algumas análises mais recentes sobre a evolução do novo transnacionalismo do movimento dos trabalhadores ver Evans (2010), Kay (2010), Munck (2010) and McCallum, J. (2013). Tarrow (2005) e Evans (2008) inserem o novo transnacionalismo do movimento dos trabalhadores no contexto da evolução geral dos movimentos sociais transnacionais. movimentos dos trabalhadores em nível nacional. Estudos das dinâmicas das campanhas globais (por exemplo, Bronfenbrenner, 2007) esclarecem as conexões transfronteiriças, mas normalmente não apresentam argumentos sobre como as trajetórias políticas a nível nacional contribuem para seus triunfos ou fracassos.

As análises dos efeitos do contexto nacional costumaram focar mais em como o estar localizado numa economia nacional privilegiada mina o transnacionalismo do movimento dos trabalhadores. Os estudos que documentam a capitulação das forças sociais do trabalho aos moldes do imperialismo Americano são um exemplo (por exemplo, Sciples, 2010). Não faltam, tampouco, análises de como a promessa do privilégio político local draga os movimentos dos trabalhadores do Sul Global na direção de coalizões dominadas pelo capital, fragilizando projetos mais amplos de solidariedade de classe (e.g. Chibber, 2007). Que as raízes nacionais possam produzir efeitos negativos sobre o trabalhismo transnacional, especialmente quando estas conferem privilégio, é evidente. Mas, uma análise equilibrada deveria examinar, também, as possibilidades de sinergias positivas entre movimentos de trabalhadores situados distintamente

\section{CONEXÕES NACIONAIS E TRANS- NACIONALISMO DO MOVIMENTO DOS TRABALHADORES}

Explorar as maneiras pelas quais as diferenças nacionais podem traduzir-se em sinergias positivas propícias ao transnacionalismo do movimento dos trabalhadores é o objetivo deste artigo. Ele é, também, uma resposta ao enigma do porquê exemplos deste novo transnacionalismo deveriam proliferar sob a égide do neoliberalismo, um regime geopolítico implacavelmente hostil ao trabalho. ${ }^{4}$

\footnotetext{
4 Como qualquer época, o neoliberalismo combina um conjunto característico de regras econômicas, estratégias e estruturas com mudanças na hierarquia geopolítica e econômica dos Estados-nação. Para uma discussão geral
} 
O declínio do poder político das forças sociais do trabalho ao nível nacional, somado à sua habilidade para distribuir benefícios econômicos aos seus membros, é uma das mais salientes características da era neoliberal. A densidade sindical caiu (especialmente no Norte); a legislação anti-sindical floresceu (particularmente nos Estados Unidos); a precariedade aumentou (em ambos, Norte e Sul) (ver Standing, 2011). Contudo, a despeito dos reveses do movimento dos trabalhadores ao nível nacional, novas conexões entre movimentos de trabalhadores nacionais e novas formas de organização global dos trabalhadores que facilitam tais ligações continuaram emergindo.

A explicação das mudanças estruturais e estratégias que facilitaram a habilidade do movimento dos trabalhadores para usar sinergeticamente as diferenças complementa as explicações globais do novo transnacionalismo do movimento dos trabalhadores e equilibra os argumentos que enxergam as diferenças nacionais em termos predominantemente negativos. Ajuda, também, a entender por que analistas encontram novas instâncias do novo transnacionalismo do movimento dos trabalhadores em meio a um clima tão adverso. Minha análise se concentrará em dois deslocamentos estruturais que facilitaram o uso sinergético das diferenças nacionais e nas mudanças das estratégias das forças sociais do trabalho a nível global que facilitaram a conexão de movimentos para além das fronteiras nacionais.

Primeiro, argumentarei que ataques violentos ao trabalho, que fazem parte do declínio da economia nacional estadunidense, estimularam a emergência de novas perspectivas e estratégias transnacionais no movimento dos trabalhadores estadunidense. Se o deslocamento de uma hegemonia nacional ascendente para uma descendente, nos Estados Unidos, estimulou o interesse pelas alianças para além das

do neoliberalismo, ver Evans e Sewell (2013). Para aqueles interessados em situar a lógica geopolítica específica da época neoliberal numa visão teórica geral sobre como as lógicas territoriais de poder interagem com a demanda do capital por lucro, o trabalho de Giovanni Arrighi (por exemplo, 1990, 1994, 1996) oferece uma lente poderosa. fronteiras, trata-se de mudança potencialmente significativa nas possibilidades para o transnacionalismo das forças sociais do trabalho. Mesmo sob ataque, o movimento dos trabalhadores estadunidense ainda comanda recursos mais elevados que a maioria dos movimentos dos trabalhadores no Sul Global.

Um segundo deslocamento estrutural, complementar, que foi chamado de "levante do Sul” (ver UNDP, 2013), aumentou a habilidade dos movimentos dos trabalhadores, ao menos em alguns dos maiores países do Sul Global, para expandir sua visão e enxergar para além das fronteiras nacionais. O tipo totalmente globalizado de capital que estes movimentos confrontam em seus próprios terrenos nacionais é um estímulo importante para o transnacionalismo. A capacidade para agir sobre estes incentivos depende tanto da força organizacional interna quanto da posição política do movimento dos trabalhadores ao nível nacional. As alianças transnacionais brasileiras são o melhor exemplo no século XXI do transnacionalismo possibilitado por este deslocamento.

O desenvolvimento da organização e da estratégia a nível global complementou estes dois deslocamentos estruturais nas posições nacionais, tornando mais fácil para o trabalho coordenar ações entre múltiplos terrenos nacionais. Esforços mais agressivos e melhor organizados, por conta das Federações Sindicais Globais (GUFs), podem facilitar a integração das estratégias de construção institucional, tradicionalmente vinculadas aos sindicatos europeus com agressivas campanhas corporativas transfronteiriças, associadas aos sindicatos estadunidenses (ver Bronfenbrenner, 2007). Ao mesmo tempo, o florescimento dos Global Framework Agreements (GFAs) fornece novos instrumentos com os quais as forças sociais do trabalho poderiam começar a tentar construir sua própria versão da governança global (ver McCallum, 2013). Estes desenvolvimentos, a nível global, dependem do engajamento dos movimentos dos trabalhadores nacionais para funcionar, mas ajudam, também, a torná-lo mais provável. 
O corpo da análise é composto por três seções, sendo o foco das duas primeiras os efeitos dos deslocamentos estruturais nas conjunturas nacionais e o da terceira as mudanças globais complementares. Na primeira seção, detenho-me na variedade de campanhas internacionais que envolvem os sindicatos estadunidenses. Eles variam das campanhas contra as oficinas precárias ${ }^{5}$ na indústria do vestuário até esforços atuais do United Auto Workers (UAW) para transnacionalizar seus esforços organizativos na indústria automobilística. Essa seção mostra o quanto a abertura para a solidariedade transnacional por parte dos sindicatos estadunidenses pode facilitar as lutas dos sindicatos locais em países pequenos como Honduras e Libéria. Ao mesmo tempo, mostra como países maiores no Sul Global, como o Brasil, por exemplo, podem tornar-se aliados significativamente importantes para os sindicatos do Norte.

A segunda seção foca na promessa criada pelo crescimento dos movimentos dos trabalhadores no Sul Global, usando o caso do Brasil como exemplo principal. O Brasil oferece um horizonte no que diz respeito à dinamização de estratégias e formas organizacionais no movimento dos trabalhadores global. O envolvimento extensivo do Brasil nos conse느 lhos de fábrica de estilo europeu ao redor do จ mundo, em redes empresariais e nos Acordos Ф் Marco-Globais (Global Framework Agreement) ڤं complementa sua participação nas campanhas $\infty$ internacionais ao estilo estadunidense, incluindo as organizadas pelo UAW e o United Steelworkers (USW).

15 A terceira seção mostra como as mesmas

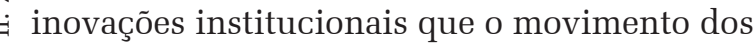
$\stackrel{\infty}{N}$ trabalhadores brasileiro julgou útil facilitaram $\vec{i}$ esforços de organização entre vários países. Esta seção destaca a interação dos sindicatos nacionais e globais na campanha para organizar os guardas de segurança do Group 4 Se-

5 [N.T. "sweatshop". Oficinas pequenas e precárias onde se trabalha em péssimas condições e com baixa remuneração. Costuma empregar força de trabalho feminina e imigrante.] curicor (G4S), como descrito por McCallum (2013). Construído sobre laços organizacionais entre a Union Network International (UNI), um Global Union (Sindicato Global) com raízes na Europa e o Service Employees Internationl Union (SEIU), um dos mais destacados praticantes das campanhas de estilo estadunidense, a campanha do G4S combinou um Acordo Marco-Global de estilo europeu com uma campanha corporativa agressiva que incluiu mobilização de base numa série de países. A análise de McCallum sobre a dinâmica das campanhas na Índia e na África do Sul reforça a importância do contexto político nacional, ilustrando, no caso da África do Sul, como uma campanha global pode contribuir para a revitalização sindical a nível nacional.

A seção conclusiva retorna à questão de até que ponto podemos generalizar a partir dos casos específicos revisados nas três seções precedentes e quais poderiam ser suas implicações para o futuro. Os tipos de conexões sinergéticas entre movimentos dos trabalhadores nacionais analisados aqui seriam efêmeros ou tenderiam a persistir e se espalhar? Quão significante e robusto são seus efeitos na arquitetura geral do movimento global dos trabalhadores? Quão vulneráveis são à fragilização ocasionada por futuras mudanças na estrutura da economia política global?

\section{UM NOVO TRANSNACIONALISMO NA "BARRIGA DA BESTA"?}

As iniciativas transnacionais atuais, levadas a cabo pelos sindicatos estadunidenses, devem superar o ressentimento e o ceticismo gerado pela conivência destes últimos com a supressão das organizações militantes de trabalhadores pelo mundo durante o apogeu da

\footnotetext{
${ }^{6}$ A "barriga da besta" [belly of the beast] foi uma denominação anti-imperialista muito usada, referente aos Estados Unidos, que remonta a José Martí. Para um uso do termo particularmente interessante ver a referência ao sindicalista guatemalteco Homero Fuentes usada por Cesar Rodriguez (2007: 68); ver citação também em Evans, 2010: 366 (nota 30).
} 
arrogância imperial (ver Scipes, 2010). Ainda assim, examinadas em si, as novas iniciativas transnacionais que envolvem os sindicatos estadunidenses parecem refletir um deslocamento significativo nas atitudes relacionadas à importância de se construir alianças com outros movimentos de trabalhadores nacionais.

Tanto o declínio da economia doméstica estadunidense quanto o terreno político doméstico cambiante associado com o neoliberalismo ajudaram a estimular a receptividade do movimento de trabalhadores estadunidense às estratégias transnacionais. No início dos anos 1990, quando a administração de Clinton, que as forças sociais do trabalho supunham ser sua aliada, demonstrou seu firme apoio à versão global do internacionalismo do capital, garantindo a aprovação do North Free Trade Agreement (NAFTA) pelo do congresso, estava claro que as fundações políticas de uma estratégia nacionalista haviam terminado. A subserviência bipartidária às prioridades corporativas transformou em quimeras os sonhos de uma proteção nacionalista. Ao mesmo tempo, o neoliberalismo reforçou a agressividade do capital nos Estados Unidos, deixando claro que, sem novas estratégias, as forças sociais do trabalho americanas definhariam.

Minha amostra ilustrativa das novas iniciativas que emergiram no neoliberalismo começa com a campanha na Russell Athletics, o apogeu do ativismo transnacional contra oficinas precárias. Em seguida, discutimos as iniciativas internacionais empreendidas por dois sindicatos industriais clássicos dos Estados Unidos - o USW e o UAW. Além de defender o "novo transnacionalismo" no movimento de trabalhadores estadunidense, a seção ilustra dois tipos distintos de chantagem patronal ao revés. $^{7}$ Por um lado, o internacionalismo es-

${ }^{7}$ Ver Evans (2010, p. 358). Remetendo-se, inicialmente, à técnica corporativista da "chantagem patronal", que utiliza locais onde o movimento dos trabalhadores é fraco para minar a sua posição onde este é forte, o termo sugere a possibilidade de se fazer o inverso - expandir o poder dos trabalhadores debilitados em seu próprio local de trabalho, através de sua conexão com trabalhadores de locais onde o trabalhismo é mais forte. [N.T. traduzimos "whipsawing" como "chantagem patronal" quando a palavra é usada sem tadunidense oferece um apoio útil aos trabalhadores em Honduras e Libéria. Por outro, as alianças com os movimentos de trabalhadores brasileiros, politicamente mais seguros, ajudam os sindicatos estadunidenses sob ataque.

Em campanhas como a da Russell, a emergência de novos atores organizacionais como os United Students Against Sweatshops (USAS) e do Workers Rights Consortium (WRC) foi crucial para colocar na mira as oficinas precárias, sendo parte integrante das campanhas, entretanto, o apoio dos sindicatos tradicionais (Rodriguez, 2007). Do papel histórico da Union of Needletrades, Industrial and Textile Employess (UNITE), na emergência dos United Students Against Sweatshops (USAS), ao papel crucial de Jeff Hermanson ${ }^{8}$ nas negociações da campanha da Russell, houve uma simbiose entre os organizadores que trabalhavam para os sindicatos e ativistas conectados com novas organizações. E, ao contrário de muitas iniciativas da parte de ONGs transnacionais (ver Seidman, 2007), as campanhas contra as oficinas precárias como aquela contra a Russell estão em "aliança com" ao invés de atuarem "em nome dos" trabalhadores insurgentes no Sul, os quais definem suas lutas em termos de demandas sindicais - reconhecimento, barganha coletiva, salários decentes, trabalho digno e proteção contra as represálias empresariais.

A vitória de 2010 na Russel, descrita por Evangelina Argueta (ver acima), já foi reconhecida de forma incontestável pelos militantes das oficinas precárias do vestuário como a maior vitória já obtida (Greenhouse, 2009) e como "o maior acordo nas manufaturas da América Central” (Graham, 2010). Um dos maiores produtores de vestuário estadunidense e principal empregador da indústria exportadora mais importante de Honduras, a

complemento. No caso do uso acompanho de "reverse" optamos por traduzi-la como "chantagem patronal ao revés"].

${ }^{8}$ Hermanson foi um militante veterano do International Ladies' Garment Workers Union (ILGWU) da indústria de vestuário e trabalhou também na América Latina com o AFLCIO Solidarity Center (ver também Anner, 2013, p. 32). 
Russell nunca havia assinado um contrato com qualquer sindicato em seus 100 anos de operação nos Estados Unidos. ${ }^{9} \mathrm{O}$ acordo de 2010 incluiu a reintegração de 1.200 trabalhadores do vestuário numa nova empresa sindicalizada (Jerzees Nuevo Dia), uma promessa de neutralidade da parte da Russell, e o acesso para os militantes a outras de suas fábricas em Honduras, que empregam cerca de 10.000 trabalhadores.

A vitória dependeu da convergência oportuna entre diversos fatores que tornaram a Russell vulnerável - de sua dependência de produtos oriundos da produção diretamente contratada na América Central à sua dependência do nicho de vestimenta universitária nos Estados Unidos. ${ }^{10}$ Mais importante, ainda, dependeu de uma reserva de habilidade estratégica acumulada e distribuída entre a rede transnacional de organizações de trabalhadores.

À primeira vista, Honduras era um terreno hostil para um triunfo organizativo no século XXI. A dominação empresarial sobre o Estado hondurenho persistiu, mesmo durante o governo populista de Mel Zelaya. O golpe militar de Estado, que derrubou Zelaya em 2009, reforçou a atmosfera de repressão, na qual a violência contra os ativistas do movimento dos trabalhadores era frequente. A elite empresarial estava permeada pela ideologia s anticomunista tradicional, na qual sindicatos iิ e comunismo eram tomados como indistintos.

¿ repressivo com uma efetividade surpreenden$\stackrel{\infty}{\circ}$ te. A legislação trabalhista hondurenha, uma

${ }^{9}$ Fundada no Alabama em 1902, a Russel juntou-se a Fruit of the Loom no império Berkshire Hathaway de Warren Buffet, em 2006.

ב్ ${ }^{10}$ Para uma análise completa da composição complexa das redes envolvidas, ver Rodriguez (2007). Para uma visão interna detalhada da campanha Kukdong, uma campanha anterior exitosa que contribuiu para a "aprendizagem ins-

titucional” que tornou possível a vitória da Russell, ver Hermanson (2004). relíquia dos velhos tempos nos quais uma boa lei do trabalho era considerada um sinal da "modernidade", era bastante progressista. A utilização era risível, mas contar com as leis nos livros ainda era uma vantagem, dado que os códigos de conduta nos Estados Unidos requeriam conformidade com as leis do trabalho locais. As manufaturas do vestuário hondurenhas, tanto domésticas quanto de propriedade estrangeira, eram consideradas fortemente atadas aos mercados estadunidenses e, portanto, vulneráveis às suas ameaças.

Uma militância movimento dos trabalhadores local forte e a dependência da elite em relação aos mercados estadunidenses criaram um potencial para a aliança transnacional. Quando os trabalhadores hondurenhos tomaram a decisão estratégica de construir laços com aliados transnacionais, havia uma estrutura à qual podiam conectar-se (Anner, 2013, p. 31). Eles se conectaram a uma arquitetura contra as oficinas precárias que estava longe de ser perfeita. A Fair Labor Association (FLA), cuja missão consistia, teoricamente, em persuadir os manufatureiros estadunidenses a cumprir os códigos de conduta, ignorou, num primeiro momento, as reclamações dos trabalhadores hondurenhos (Anner, 2013, p. 32). A despeito disto, a USAS foi exitosa em ameaçar o mercado de vestimenta universitária, bastante lucrativo para a Russell.

No momento do acordo, aproximadamente 110 universidades finalizaram seu contrato com a Russell e a USAS começou a buscar seus maiores clientes não universitários (Anner, 2013, p. 34). A vitória final foi um produto transnacional que utilizou fontes institucionais do próprio ambiente da Russell para compensar os empresários recalcitrantes locais e a falta de uma atuação estatal confiável em Honduras. Os representantes da CGT foram aos Estados Unidos para envolver o empresariado da matriz da Russell nas negociações finais. O acordo final foi viabilizado por conta de uma arbitragem orquestrada nos Estados Unidos. 
O caso Russell é excepcional, mas não é único. A luta exitosa para formar um sindicato independente na Bridgestone-Firestone, nas plantações de seringueiras da Libéria, é uma variação dos recursos organizacionais sediados nos Estados Unidos para pressionar as operações estrangeiras de uma corporação estadunidense num país pequeno e pobre. As condições nas plantações eram tão execráveis que o International Labor Rights Forum (ILRF) processou a Bridgestone-Firestone em 2005 por impor "condições de trabalhos semelhantes às escravas” (ILRF, 2005). O USW, que organiza os trabalhadores estadunidenses da BridgestoneFirestone, teve seus próprios problemas com a companhia e viu uma oportunidade de colocar a Firestone na defensiva.

Quando os trabalhadores das plantações fizeram uma greve sem o apoio do seu sindicato, ${ }^{11}$ os sindicatos da USW Bridgestone-Firestone nos Estados Unidos coletaram fundos de apoio aos trabalhadores grevistas. Depois, quando o recém-formado Firestone Agricultural Worker Union of Liberia (FAWUL) disputou uma eleição contra o sindicato amarelo estabelecido da Firestone, o USW, a ICEM (International Federation of Chemical, Energy, Mine and General Workers' Unions) e o AFLCIO (American Federation of Labor/Congress of Industrial Organizations) Solidarity Center forneceram apoio e a FAWUL ganhou a eleição internacionalmente monitorada (Kazdin). Neste caso, o apoio dos aliados estadunidenses foi menos fundamental do que no caso da Russel, em parte devido ao fato de o recém-eleito governo de Ellen Johnson Sirleaf haver sido favorável aos trabalhadores da Firestone, mas a formação de um sindicato independente, com 5.000 membros no setor exportador mais importante do país, foi um marco semelhante à vitória na Russell.

Os casos, hondurenho e liberiano, demonstraram que, sob o neoliberalismo, os

${ }^{11}$ [N.T. "wildcat strike”. Trata-se de uma greve de trabalhadores geralmente sindicalizados que, contudo, não conta com o apoio da entidade.] trabalhadores militantes em países pequenos e pobres, dependentes economicamente dos Estados Unidos, puderam alavancar conexões transnacionais com os trabalhadores americanos. Tais alianças transnacionais ajudaram a mudar o território nacional. Os movimentos dos trabalhadores, que foram por eles revigorados, adquiriram uma nova possibilidade de se tornarem atores políticos locais.

Estes casos ilustram uma abertura às alianças transnacionais por parte dos sindicatos estadunidenses cuja origem radica da indústria de bens de consumo, onde os conflitos a respeito da disposição geográfica dos postos de trabalho foram tradicionalmente considerados uma barreira para a construção de uma solidariedade Norte-Sul (Evans, 2010, p. 355). Eles são interessantes, também, porque são construídos sobre alianças entre sindicatos tradicionais e as novas ONGs, vinculadas ao mundo do trabalho, cujo estilo organizacional e ideológico é tido como dissonante em relação ao sindicalismo tradicional, o que sugere que conexões transnacionais e conexões que ligam estilos organizativos devem estar sinergeticamente relacionadas (Anner and Evans, 2004).

Infelizmente, apenas um número limitado de países se encaixa no perfil de Honduras e Libéria. As vitórias nos países onde tal é o caso, mesmo se multiplicadas, podem, dificilmente, desequilibrar a balança do poder global na disputa entre o movimento dos trabalhadores e o capital. A menos que o conjunto de novas conexões nacionais inclua uma gama mais ampla de países, seu impacto na arquitetura das forças sociais do trabalho global será mínimo.

Uma mirada mais ampla sobre o USW mostra como um conjunto amplo de alianças transnacionais, que conectam uma série de países, pode emergir a despeito da relação tradicionalmente ambivalente de um país rico com seu sindicato de bens de consumo. A USW definiu sua agenda antiglobalização através do dumping ao aço importado no porto de Seattle, em 1999, e deu as boas vindas às tentativas da administração Bush de impor quotas ao aço brasileiro 
importado. Porém, seu apoio aos trabalhadores liberianos da plantação de seringueiras foi consistente, ao mesmo tempo, com uma história de iniciativas transnacionais. A luta exitosa dos Steelworkers (sindicato dos metalúrgicos) contra Marc Rich e o empresariado da Ravenswood Aluminium é uma das campanhas transnacionais mais célebres da memória recente (Juravich and Brofenbrenner, 1999). ${ }^{12}$

Mais relevante, ainda, para o ponto de vista desta análise, é a aliança do USW com os sindicatos dos mineiros mexicanos, o SNTMMSSRM (Sindicato Nacional de Trabajadores Mineros, Metalúrgicos, Siderúrgicos y Similares de la República Mexicana), conhecido como os Mineros (Davis, 2012). A relação USW-Mineros, não somente ilustra a abertura da USW às alianças transnacionais, como, também, mostra o quanto uma crescente receptividade às alianças transnacionais por parte de sindicatos, outrora corporativos no Sul, pode ser um complemento crítico às iniciativas transnacionais vindas do Norte.

Confrontados com a repressão governamental à icônica greve de 1989, na mina de cobre em Cananea, os Mineros do México não estavam, ainda, prontos para assumir as alianças com os sindicatos estadunidenses como parte de sua estratégia. Em 2005, uma série de ataques virulentos vindos do Estado mexicano mudou suas opiniões. Eles assinaram uma aliança estratégica com o USW, filiado tanto à International Metalworkers Federation (IMF) quanto à $\infty^{\circ}$ International Federation of Chemical, Energy, Mine and General Workers' Unions (ICEM), e sustentaram uma greve de solidariedade de um dia em apoio à greve do USW na subsidiária esa tadunidense do Grupo México (Davis, 2012, p.

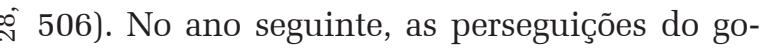
verno forçaram o presidente dos Mineros, Napoleon Gomez Urrutia, a exilar-se no Canadá, onde contou com o apoio do USW. Em 2010, o presidente do USW, Leo Gerard, e Gomez Urru-

${ }^{12}$ A USW já havia criado um sindicato transnacional em 2008, através da criação, juntamente com o britânico Unite the Union, de 1.5 milhões de membros, de uma nova entidade chamada Workers Uniting. tia anunciaram uma comissão para explorar a formação de um único sindicato Norte Americano. O sindicato único Norte Americano não se materializou, mas, se este tivesse sido o caso, agregaria, aproximadamente, 200.000 Mineros aos quase 800.000 membros do USW nos Estados Unidos e no Canadá, criando um dos maiores sindicatos no hemisfério.

Se a aliança USW-Mineros ilustra ainda mais os possíveis benefícios do novo transnacionalismo estadunidense para os sindicatos do Sul, o apoio que o USW recebeu como consequência de sua filiação ao Gerdau Workers World Council (GWWC) é um dos melhores exemplos de como os sindicatos estadunidenses podem se tornar beneficiários da chantagem patronal ao revés.

O estímulo inicial para o GWWC foi a agressiva expansão nacional e global do maior produtor privado de aço do Brasil, a Gerdau, que, em 2003, tornou-se a quarta maior produtora de aço do mundo, com filiais na América do Norte e na Europa (Gray, 2009, p. 89). No Brasil, a Confederação Nacional dos Metalúrgicos, filiada à Central Única dos Trabalhadores (CUT) percebeu que não podia defender seus direitos e salários contra a Gerdau com base nas lutas individuais e locais contra os empresários de plantas individuais. Eles construíram, primeiro, uma rede nacional de trabalhadores da Gerdau. Trocas entre os trabalhadores da USW canadense, fundada pela "SteelWorkers Humanity Fund", também do Canadá, iniciadas em 1997, principiaram uma iniciativa transnacional. Em 2003, os trabalhadores da Gerdau do Brasil, Argentina, Chile, Uruguai, Canadá e Estados Unidos reuniramse para discutir a possibilidade de construir uma rede transnacional (Gay, 2009, p. 81-92).

Ao mesmo tempo, a produção de aço nos Estados Unidos estava se transferindo para fábricas pequenas, geridas por firmas hostis ao movimento dos trabalhadores em estados onde vigem leis antisindicais, no sul do país, debilitando a habilidade do USW para organizar, ou mesmo manter, os contratos existentes. Os 
problemas do USW e os esforços da rede da Gerdau convergiram em 2005, quando conversas sobre contratos numa planta da Gerdau, em Beaumont, Texas, terminaram em uma interrupção da produção depois que a Ameristeel, subsidiária da Gerdau, demandou, como parte de sua "melhor oferta derradeira", demissões de férias, hora extra e direitos de antiguidade.

O USW percebeu que uma campanha de conscientização teria de estender-se ao país de origem da Gerdau para ser efetiva, e os Metalúrgicos da CUT estavam preparados para oferecer solidariedade. Sem tentar recapitular a história desta longa e dramática campanha (Gay, 2009, p. 98-122), basta dizer que, pressionada tanto em casa quanto por uma campanha apoiada na rede da GWWC, o empresariado da Gerdau no Brasil decidiu, finalmente, que a abordagem linha dura antitrabalhismo dos empresários da Ameristeel nos Estados Unidos era contra-produtiva. Em 2007, a USW podia negociar contratos nas plantas onde a produção havia sido interrompida. ${ }^{13}$

Outro sindicato tradicional de bens de consumo, o UAW, busca, atualmente, uma variação ainda mais interessante da estratégia da chantagem patronal ao revés. Em 2010, o novo presidente da UAW, Bob King, fez da sindicalização das montadoras estrangeiras (conhecidas como "transplantas"), no Sul dos Estados Unidos, seu principal objetivo industrial. ${ }^{14}$ Fazia sentido. A menos que possa sindicalizar estas plantas, o UAW está condenado a assistir ao número de trabalhadores das indústrias encolher. $\mathrm{O}$ problema com a iniciativa de King estava em que soava como um projeto estilo "missão impossível”. Apesar de sindicalizadas em seus países de origem, as firmas estrangeiras estavam contentes

${ }^{13}$ Deve-se sublinhar que a GWWC é tanto uma aliança Sul-Sul quanto Sul-Norte, preocupada, igualmente, com os efeitos da expansão da Gerdau para o resto da América Latina. Uma campanha recente contra as demissões em companhias adquiridas pela Gerdau na Colômbia é um exemplo.

${ }^{14}$ Embora seja legítimo ligar a estratégia da UAW à presidência de King (e à sua antiga influência como um diretor organizacional), minha afirmação sobre a forma estratégica de pensar é baseada, exclusivamente, em minha interpretação das ações e declarações públicas de King e da UAW, não em comunicações pessoais. em tirar proveito do ambiente antisindicato do sul estadunidense. Eles mitigaram as motivações econômicas para que os trabalhadores se organizassem oferecendo bons salários em comparação com os padrões locais vigentes.

A resposta de King a esta missão impossível deu-se em várias frentes. Na planta da VW (Volkswagen) em Chattanooga, Tenessee, o UAW desenvolveu uma estratégia baseada na chantagem patronal ao revés, tradicionalmente estruturada, baseada no poder institucionalizado que a IG Metall havia construído em sua base alemã. Como um sistema de conselho tolerante aos sindicatos tornou-se parte integrante do modus operandi da VW ao redor do mundo e, pela lei estadunidense, requer um sindicato, o IG Metall e o UAW puderam persuadir a VW a permanecer neutra nas eleições sindicais. ${ }^{15}$

O resultado foi uma confrontação do poder econômico transnacional com a cultura política local. A companhia deveria permanecer neutra, mas os políticos locais no Tenessee foram loquazes em sua condenações à UAW como "estrangeira", no Sul, e da Volkswagen como "antiamericana" em seu afã por conquistar votos. No fim, a chantagem patronal ao revés quase funcionou, mas não muito. O UAW perdeu a eleição por uma margem de 86 votos (712 a 626), aproximando-se mais dos esforços anteriores, menos apoiados transnacionalmente, para organizar as transplantas do Sul, mas segue sendo uma derrota e uma indicação dos limites da capacidade das estratégias transnacionais para desequilibrar a balança local das forças políticas nos Estados Unidos. ${ }^{16}$

A outra estratégia de King para organizar as transplantas foi mais inovadora, embora também fosse "uma missão impossível". Ele

1588 das 104 plantas da VW ao redor do mundo possuem conselhos de trabalhadores e a lei estadunidense faz da existência de um sindicato um pré-requisito para a existência de um conselho de fábrica. Ver Automotive News, 10/7/2013.

${ }^{16}$ O esforço da UAW em 2001 para organizar a planta da Nissan em Smyrma, Tenneesse, terminou em derrota por uma margem de 2 a 1 (Aschoff, 2014). Os críticos de esquerda não estavam impressionados com a margem, atribuindo a derrota à inabilidade da UAW para conectar-se aos trabalhadores de base (Aschoff, 2014; Early, 2014). 
se focou na planta da Nissan em Canton, Mississippi, na qual trabalhadores comuns costumavam habitar a metade superior da tabela de distribuição de renda e um argumento econômico por parte dos sindicatos não ganharia muita adesão (Greenhouse, 2013). Como alternativa, a campanha focou no sindicato como um veículo capaz de dar voz aos trabalhadores em suas vidas no trabalho. O UAW concebeu as reclamações por mais voz no trabalho como o próximo passo para a inconclusa agenda de direitos civis no Mississippi, o que surtiu efeito para a força de trabalho predominantemente afro-americana da planta. Com esta abordagem, a campanha ganhou o apoio da National Association for the Advancement of Colored People (NAACP) local (Compa, 2013).

Por atraente que pudesse ser a campanha a nível local, a UAW percebeu que, enquanto a batalha fosse levada a cabo somente em Canton, exerceria pouca influência sobre o empresariado global da Nissan. Quando os trabalhadores da Nissan se reuniram no Tugaloo College, no início de 2013, Vagner Freitas, o presidente da CUT brasileira, estava entre os presentes. Trazer o presidente da CUT à Canton não foi somente um exercício de "diplomacia trabalhista”. Na estratégia global da Nissan para construir um nicho de mercado, o Brasil 을 era um elemento crucial, fazendo deste último จ um elemento importante também para o UAW.

Фं Vencer no Sul dos Estados Unidos dependeu da construção de uma aliança durável entre os $\infty$ países do Sul Global.

Brasil era o quarto maior mercado automobilístico no mundo e crescia com mais velocidade que os mercados no Norte Global. ${ }^{17}$ Era um mercado no qual a Nissan viu uma oportunidade ๙ para expandir-se. Se o UAW pudesse lograr um $\Rightarrow$ acordo plausível para fazer do sucesso da expansão planejada da Nissan no Brasil uma parte de sua barganha, o custo de impedir a sindicaliza-

17 De 2005 a 2011, o mercado automobilístico brasileiro marcou $12 \%$ de crescimento ao ano, comparado com cerca de 2\% nos Estados Unidos. No ano fiscal de 2011, as vendas da Nissan quase dobraram no Brasil (Nissan 2012 Annual Report, p. 16). ção na Canton cresceria dramaticamente.

Mudar o ambiente político para a Nissan no Brasil requereria mais do que uma campanha para angariar apoio para uma greve. Demandaria um investimento de longo prazo para criar laços com o movimento dos trabalhadores brasileiro e despertar o interesse da mídia e da cultura de massa brasileira a respeito da base antisindical das transplantas no Sul dos Estados Unidos. O UAW investiu em duas organizações no Brasil. Bob King passou uma semana no Brasil, em meados de 2012, para marcar a abertura do escritório da UAW no Brasil, discursou no congresso nacional da CUT, e encontrou-se com o presidente da câmara dos deputados, Marco Maia (também um antigo metalúrgico). Quatro meses depois, o UAW bancou um estande na exposição de carros em São Paulo para construir relações com a mídia local.

A mensagem de King ao Brasil era a de que os sindicatos estadunidenses admiravam seus colegas brasileiros e ganhariam em aprender com eles, que o declínio do poder dos sindicatos nos Estados Unidos estava tornando cada vez mais precária sua classe trabalhadora e que as alianças transnacionais deveriam ser parte da resposta. Os líderes do trabalhismo brasileiro estavam impressionados com o fato de que o UAW houvesse começado construindo laços e foram, por isso, mais simpáticos à campanha. A ênfase nos direitos civis na campanha do Mississippi também repercutiu no Brasil ( Donizetti, 2013). Quando a CUT anunciou seu acordo de 2013 com a AFL-CIO, "combater as práticas antisindicato na planta da Nissan no Mississippi” foi a única ação conjunta concreta destacada. ${ }^{18}$ Em Outubro de 2013, o ex-presidente do Brasil, Luís Inácio Lula da Silva, escreveu uma carta ao presidente da Nissan Gohsn, dizendo que, embora a considerasse "uma companhia global impressionante", que "mantinha ${ }^{18}$ Ver a nota conjunta (em discrepância com o editorial do jornal [op. ed]) das lideranças dos metalúrgicos da Força e da CUT em Folha de São Paulo, 19 de novembro, 2012 pg. 3. Como sublinha Anner (2003, 2011), a Força tem sido, tradicionalmente, menos internacionalista que a CUT, sendo esta ação de articulação, portanto, um indicador importante do aprofundamento dos laços institucionais da UAW no Brasil. 
boas relações com os sindicatos no Brasil e em outros países”, estava profundamente preocupado com a campanha antisindicato, que conduzia a Nissan nos Estados Unidos, e esperava uma “ação reparadora” (Lula, 2013).

Criar um sindicato local com alguns milhares de trabalhadores no Mississippi seria tão consequente para a economia política local quanto foi o estabelecimento de um sindicato independente para os 5.000 trabalhadores da plantação de seringueiras para a economia política local da Libéria, restando saber se a estratégia de King vencerá. Mesmo que a pressão do Brasil sobre a Nissan seja efetiva, a ferocidade local da oposição política será proporcional à magnitude do efeito de sindicalização. Vitória ou derrota, a iniciativa permanece um exemplo da consciência dos sindicatos tradicionais industriais estadunidenses a respeito do papel essencial que devem cumprir as alianças globais na sobrevivência da estratégia doméstica.

Na medida em que o UAW, assim como o USW, é um sindicato cujas tradições e cultura política são enraizadas na indústria clássica de bens de consumo, estes exemplos possuem implicações que estão para além da simples sinalização a uma abertura crescente às alianças transnacionais da parte do trabalhismo estadunidense. Ambos os exemplos sugerem que os velhos argumentos de que os conflitos sobre a distribuição geográfica dos postos de trabalho em indústrias de bens de consumo minam a possibilidade de iniciativas transnacionais deveriam ser revisados.

\section{AS ARTICULAÇÕES TRANSNACIO- NAIS DO "SUL INSURGENTE"}

Assim como o Brasil cumpre um importante papel na visão da Nissan sobre seus lucros globais, os maiores países do Sul Global são centrais para a busca geral do capital por expandir lucros globais. Estes países não são somente "grandes economias dinâmicas com uma grande influência política” (UNDP, 2013); eles são arenas de contestação sociopolítica, na qual as lutas nacionais do movimento dos trabalhadores são entrelaçadas às estratégias transnacionais. O Brasil é o caso óbvio para explorar o potencial para interações positivas entre tais terrenos e a arquitetura das forças sociais do trabalho ao nível global. Há duas questões aqui. Primeiro, que papel devem cumprir os movimentos dos trabalhadores nos maiores países do Sul global para construir uma arquitetura das forças sociais do trabalho ao nível global? Segundo, e reciprocamente, que tipo de papel deve cumprir uma arquitetura mais efetiva das forças sociais do trabalho para provocar inflexões positivas na evolução destes terrenos nacionais?

O papel do Brasil, no suporte aos esforços nascentes dos sindicatos estadunidenses para construir alianças transnacionais, já foi ressaltado, mas o volume das alianças transnacionais do Brasil envolveu sindicatos europeus, redes empresariais, acordos de padrões internacionais e Federações Sindicais Globais (Global Union Federations - GUFs) estreitamente ligados aos sindicatos europeus. As primeiras alianças transnacionais do Brasil foram construídas em torno de lutas com o regime militar brasileiro, a respeito dos direitos sindicais nos anos 1970 (Anner, 2011, p. 125). Por exemplo, os sindicalistas do IG Metall, que trabalhavam na Volkswagen na Alemanha, apoiaram os esforços dos trabalhadores da planta brasileira da Volkswagen em sua luta para conquistar direitos sindicais básicos.

Depois, as lutas econômicas ganharam protagonismo. Os líderes dos sindicatos brasileiros aprenderam o alemão e se tornaram participantes ativos nos conselhos de trabalho globais das companhias automobilísticas alemães, tanto da Volkswagen quanto da Daimler. ${ }^{19}$ Este trabalho gerou frutos em 2001 quando a liderança da CUT usou as conexões alemãs para denunciar a intransigência dos empresários de subsidiárias localizadas em

${ }^{19}$ Em 2002, o Brasil possuía mais membros que qualquer outro país nos Volkswagen Worldwide works Council, excluindo-se a Alemanha (Rüb, 2002: 23). 
São Paulo, efetivar negociações com a sede da VW em Wolfsburg, sediar a produção de um novo modelo no Brasil e mitigar demissões planejadas (Anner, 2011, p. 128). As alianças Alemanha-Brasil também produziram ações solidárias para impedir que a companhia compensasse perdas de produção por conta das greves com o aumento de horas extras no Brasil (Anner, 2011, p. 130-131).

Alianças com outros sindicatos e a participação em conselhos de trabalho foram complementadas pelo uso dos Acordos-Marcos Globais (IFAs/GFAs), concebidos para vincular operações pelo mundo aos padrões aceitos pela companhia matriz em sua sede. Como os conselhos de trabalho ao redor do mundo, os IFAs são um dispositivo característico da Europa. Concebido em termos bastante genéricos, os IFAs são "capengas" na falta de um poder sindical complementar, mas, no contexto da organização local e das redes transnacionais do movimento dos trabalhadores, podem ser ferramentas valiosas (Fitcher; Helsen, 2011; McCallum, 2013; Stevis; Boswell, 2007, 2008).

$\mathrm{O}$ uso que fizeram os metalúrgicos brasileiros do IFA da Daimler, assinado em 2002, exemplifica sua possível utilidade. Como o IFA da Daimler vale tanto para os fornecedores quanto para as próprias filiais, os metalúrgicos 12 da Mercedes no Brasil puderam usá-lo como จ um instrumento para fortalecer o poder sindiФं cal nas plantas fornecedoras menos organizadas, através da luta contra as violações da IFA $\infty$ nos fornecedores, fazendo os empresários da em prol de sua aplicação Fichter e Helfen, 2011:99-100).

Os sindicalistas brasileiros complemena taram amplas colaborações com as Federações

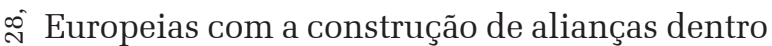
$\overrightarrow{~ d a s ~ e m p r e s a s ~ i n d i v i d u a i s . ~ A ~ l o n g a ~ h i s t o ́ r i a ~ d a ~}$ colaboração entre a Dutch Federation of trade Unions (FNV) e a CUT é um bom exemplo. Trabalhando com o Instituto Observatório Social da CUT, a FNV apoiou a pesquisa sobre o cumprimento dos padrões fundamentais de trabalho por parte das corporações multinacionais às quais desejam aderir. Apoiou, também, o projeto "CUTMulti” (Ação de confrontação às multinacionais), que foi concebido para criar redes entre todos os sindicatos (dentro e fora da CUT) que organizam trabalhadores em uma corporação multinacional particular (Jakobsen, 2007:154). Embora se tenha focado intensamente nas filiais das companhias da Dutch (Akzo-Nobel, Phillips etc.), a CUT-Multi estendeu-se para outras multinacionais de outras origens. Uma das redes empresariais mais desenvolvidas é a rede BASF (Badische Anilin und Soda-fabrik, uma Companhia Química Alemã) que se estendeu pela América Latina e foi ativada em apoio a U.S. Steel Workers na América do Sul. Em 2005, novamente com o apoio da FNV, a metodologia de pesquisa do Observatório foi compartilhada com organizações em seis outros países da América Latina, terminando por criar a "Latin American Network for Research on Multinational Companies" (REDLAT) (Veiga e Jakobsen, 2011: 92-93).

O Brasil também entendeu que as GUFs podem cumprir um papel doméstico útil. As GUFs devem manter-se ostensivamente neutras face à multiplicidade das confederações que surgiram no ambiente relativamente simpático ao movimento dos trabalhadores no Brasil. Desta forma, as GUFs podem cumprir, com frequência, um papel útil na negociação das campanhas mais amplas. A "Campanha para o trabalho decente na Copa do Mundo da FIFA de 2014" da Building and Wood Worker's Internationl (BWI) é um bom exemplo. Demandou a construção de uma campanha por parte dos sindicatos da construção, filiados a cinco confederações brasileiras diferentes, algo que teria sido difícil para a CUT ou qualquer outra confederação individual brasileira. Da mesma forma, a Public Services International (PSI) se vê engajada, frequentemente, nas negociações diplomáticas entre os sindicatos brasileiros, filiados às confederações distintas, que trabalham na saúde ou em outros campos dos serviços.

O Brasil demonstra como um terreno favorável pode tanto estimular articulações de redes internacionais de trabalhadores quanto 
delas se beneficiar. Mostra como um movimento dos trabalhadores bem organizado pode engajar-se tanto em campanhas de confronto associadas à postura combativa do movimento dos trabalhadores estadunidense em relação às empresas intransigentes, quanto no foco de construção institucional, atribuído aos sindicatos europeus. A habilidade do movimento dos trabalhadores no Brasil para lidar com os dois tipos de estratégias é a marca registrada de sua sagacidade para tornar-se um nexo central para as redes transnacionais de trabalhadores.

O Brasil oferece um modelo proveitoso para o movimento global dos trabalhadores, que pode aproveitar-se do fortalecimento das forças sociais do trabalho nos maiores países do Sul Global, mas, também, ilustra o útil papel da infraestrutura global, tanto como apoio para as campanhas dentro dos territórios nacionais quanto de suporte à construção de conexões entre os movimentos nacionais de trabalhadores. As conexões baseadas numa conjuntura política nacional ou em alianças bilaterais devem ser complementadas com redes e campanhas entre vários países, que, por sua vez, requerem um aparelho global mais desenvolvido do que aquele com o qual o movimento dos trabalhadores pôde contar no passado.

\section{CONECTANDO MÚLTIPLOS TERRI- TÓRIOS NACIONAIS}

Os impérios de corporações multinacionais nunca se limitam a conectar unicamente dois mercados nacionais. O movimento global de trabalhadores tampouco pode dar-se por satisfeito com as conexões bilaterais. As conexões nacionais devem ser eventualmente imersas em estruturas mais amplas se querem exercer um poder real na economia global. O movimento dos trabalhadores deve construir sua própria versão da governança global. As campanhas corporativas, para além das fronteiras, redes empresariais, IFAs, e GUFs, são todas formas capazes de ligar múltiplos terrenos nacionais, e sua utilização acelerou rapidamente, no neoliberalismo (Bronfenbrenner, 2007; Munck, 2010), uma mudança bem-vinda com relação à quietude relativa da "era de ouro do capitalismo” do pós-segunda guerra.

Tradicionalmente, as estruturas sindicais internacionais, que deveriam prover a espinha dorsal de tal projeto, foram subfinanciadas pelos sindicatos nacionais (Jakobsen, 2001). Os tempos difíceis do neoliberalismo promoveram iniciativas suficientes para que os movimentos nacionais dos trabalhadores investissem recursos suficientes nas estruturas sindicais globais? Há esperança de que estas organizações se tornarão, por sua vez, mais efetivas em articular a interação dos movimentos nacionais? Os céticos rechaçarão ambas as possibilidades, mas poderão estar perdendo algumas oportunidades promissoras.

As GUFs, a concretização setorial do movimento sindical global, evoluíram desde seus dias como "International Trade Secretariats". No início da "era de ouro do capitalismo” pós-segunda guerra, o International Trade Secretariats era tímido e setorialmente especializado. A expansão destas organizações setoriais globais se dá em contraste com a relativa estagnação na filiação sindical ao nível nacional. Planejam um papel mais ativo, não só em terrenos favoráveis como o Brasil, mas, também, em campanhas entre vários países. ${ }^{20}$

Embora a densidade sindical tenha caído na maior parte dos países ao redor do mundo, com a filiação decrescendo em termos absolutos em alguns países, a filiação e o número de membros das GUFs continuam a subir até atingir cinco vezes o índice seu tamanho na metade do século. ${ }^{21} \mathrm{O}$ tamanho não é, necessa-

${ }^{20}$ Focar o lado convencional da arquitetura global me força a negligenciar as organizações entre vários países menos convencionais como a SIGTUR (Southern Initiative on Globalization and Trade Union Rights), às quais pertencem a CUT, a COSATU e a KCTU (Korean Confederation of Trade Unions) e que requerem uma análise separada. Ver Webster, Lambert and Bezuidenhout, 2008; Evans, 2010.

${ }^{21}$ Estas comparações de horas extras são um pouco imprecisas já que se referem somente aos filiados à Confederation of Free Trade Unions (ICFTU) e à International Trade Union Confederation (ITUC). Faltam-nos dados sobre as organizações setoriais filiadas à World Federation of Trade 
riamente, um indicador da perspicácia estratégica ou da efetividade mobilizacional, mas disponibiliza capacidades e recursos para as iniciativas estratégicas. As GUFs de hoje são enormes. A IndustriALL, o sindicato global híbrido, possui 50.000.000 de membros e 800 sindicatos nacionais filiados ao redor do mundo. Os dois maiores setores de serviços das GUFs - PSI e UNI - possuem juntos 40.000.000 membros e 1.500 sindicatos filiados.

Junto com o novo tamanho e escopo das GUFs, cresceu o interesse em forçar campanhas para assinar os IFAs ou GFAs, como os IFAs discutidos pela Volkswagen e Daimler no Brasil. O primeiro IFA foi assinado em 1988; na virada do milênio, havia, ainda, somente 8; em 2006, havia 55 (Stevis e Boswell, 2007: 112-113). Provou-se quase impossível fazer com que as companhias sediadas nos Estados Unidos assinassem os IFAS (Fitcher e Helfen, 2011; Stevis e Boswell, 2007, 2008), mas o IFA do International Metal Federation de 2012 com a Ford propõe que o novo transnacionalismo dos Estados Unidos deva incluir a pressão para os IFAs nas firmas multinacionais sediadas nos Estados Unidos (IMF, 2012).

Na medida em que um IFA possui jurisdições que são tão multinacionais quanto as companhias e GUFs que as assinaram, a verdaم deira questão está em se podem difundir ganS hos obtidos em ambientes onde o movimento Фं dos trabalhadores é mais forte para os terrenos nacionais menos favoráveis. Stevis e Boswell œ (2007, p. 175) argumentam que as "chances de

$\therefore$ das fronteiras, tais como as campanhas de cons๙ cientização". Em suma, eles apontam para uma combinação entre uma construção institucional de estilo europeu e as campanhas corporativas de estilo estadunidense como uma maneira de tornar os IFAs uma ferramenta mais potente para o movimento global de trabalhadores.

O melhor estudo de caso sobre como um Unions (WFTU) e à World Confederation of Unions (WCL).
IFA pode ser integrado a uma campanha corporativa entre vários países é a campanha G4S para organizar os guardas de segurança. A campanha G4S é, geralmente, tomada como o arquétipo da campanha corporativa do início do século XXI. Ela mostra como a combinação entre os IFAS e campanhas globais depende da construção de uma arquitetura internacional correspondente, capaz de combinar esforços mais enraizados de um conjunto diverso de sindicatos nacionais com o escopo de negociação mundial de um Sindicato Global. Evidencia que as estratégias globais são importantes no agora globalizado setor de serviços, bem como na manufatura. E fornece ideias úteis sobre a maneira pela qual territórios nacionais moldam e podem ser moldados pelas campanhas globais.

A análise de Jamie McCallum (2013) da campanha G4S nos fornece uma imagem teórica provocativa de que como funcionou a campanha tanto ao nível global quanto ao nível nacional. Os atores-chave nas análises de McCallum incluíam a Rede Sindical Internacional (Union Network InternationalUnion Network International - UNI), a maior do setor de serviços das GUFs, o SEIU, uma campeã estadunidense de campanhas corporativas agressivas, a South African Transport and Allied Works Union (SATAWU), a Indian National Trade Union Congress (INTUC), e o Center of Indian Trade Unions (CITU).

Como o maior mercado do G4S, a Índia, era um elemento crucial na campanha global, a África do Sul e uma série de outros países no Sul Global cumpriram um importante papel também. Contudo, as origens da campanha do G4S não foram a Índia ou a África do Sul, mas a convicção do SEIU de que somente uma campanha global poderia quebrar barreiras que a impediam de organizar o maior empregador de guardas de segurança dos Estados Unidos. Partes decisivas da liderança do SEIU decidiram, como relatou Harold Myerseon (2009), "se vocês querem organizar os guardas da segurança de Chicago, terão de organizar todo o planeta”. As origens do novo transnacionalismo 
neste setor de serviço são notavelmente similares às dinâmicas já descritas nos casos que envolvem os automóveis e o aço. Assim como o USW e o UAW tiveram de encontrar estratégias globais para confrontar o poder dos capitais globais sobre seus membros nos Estados Unidos, a divisão do SEIU Property Services viuse enfrentando empregadores que não eram mais locais, ou mesmo nacionais, mas globais. Quando o G4S, sediado na Inglaterra, adquiriu a Wackenhut, uma das maiores empregadoras de guardas de segurança dos Estados Unidos, o ímpeto para montar uma campanha global para organizar os guardas de segurança nos Estados Unidos foi posto em movimento.

A lógica de construir parcerias transnacionais foi, entretanto, muito distinta no caso do G4S do caso da campanha do UAW e do USW. Nenhum mercado isolado de um país era suficientemente importante a ponto de forçar o G4S a negociar. A campanha teve de ser feita em múltiplos terrenos, não precisando, por isso, de aliados que fossem individualmente poderosos. Trabalhar através do UNI e do SEIU construiu uma estratégia Lilliputianos versus Gulliver, na qual os sindicatos oriundos de contextos múltiplos, nenhum deles particularmente forte em seus contextos nacionais, convergiram para forçar a corporação Gulliver a negociar. Os sindicatos, num conjunto impressionante de países, foram envolvidos, variando de países no Norte, como os Estados Unidos e a Inglaterra, aos maiores países do Sul, como Indonésia, Índia e África do Sul, e aos países menores no Sul como Malawi e Ghana.

A peça organizacional chave foi o UNI. Fundado em 2000 e tendo assinado seu primeiro GFAs em 2001, na primavera de 2013, o UNI havia assinado 48 acordos globais, mais que qualquer outra GUF. A base organizativa agressiva do UNI é uma consequência direta tanto do apoio que esta recebeu do SEIU quanto da infusão de lideranças com experiência em trabalhar nas campanhas do SEIU. Christy Hoffman, que veio para o UNI com uma extensa experiência e se tornou Deputy
General Secretary em 2010, substituindo o cofundador do UNI que estava se aposentando, Philip Bowyer, exemplifica a nova geração de lideranças. Transformar uma variada gama de sindicatos a nível nacional num poder coletivo que poderia forçar a G4S a assinar um IFA dependeu da aproximação da estrutura organizacional englobante do UNI no intuito de compor uma campanha organizacional entre vários países. Assim, o papel do UNI exemplifica a possibilidades de transformar as GUFs em veículos para as campanhas organizacionais entre diversos países.

Uma campanha global foi a condição sine qua non para trazer a G4S para a mesa de negociação, mas a campanha teve que ser lutada em territórios nacionais distintos. Cada campanha nacional refletia um contexto político e uma história sindical local. Ao mesmo tempo, ser parte de uma campanha global gerou um impacto nos sindicatos nacionais envolvidos. A análise de McCallum da África do Sul e da Índia mostra como a política nacional pode direcionar uma campanha global em dois tipos de campanhas bastante diferentes, em contextos nacionais distintos, bem como a forma como a participação na campanha global pode remodelar as estratégias dos sindicatos nacionais.

Na África do Sul, a campanha global incentivou a revitalização do sindicato compatriota nacional, o SATAWU (McCallum 2011, 2013: cap. 4). Os funcionários da UNI que trabalham na África do Sul enfatizaram a organização que foi fundamental para ajudar o SATAWU a transformar-se de um sindicato de serviços num sindicato militante. A participação da SATAWU na campanha ajudou a estimular a organização de mais 3.000 guardas de segurança, aumentando em $40 \%$ o número de organizados desta categoria.

Os efeitos locais da assinatura do Acordo Marco-Global pela alta administração da G4S em Londres também corroborou o potencial das GFAs. Longe de ser uma peça abstrata do papel global, o GFA revigorou os militantes locais, dando-lhes um senso de autoridade 
que superou a recalcitrância dos empresários locais. MacCallum (2013: 118) cita um organizador local dizendo, "essa é minha cópia do acordo global. É como uma Bíblia. Quando os empresários me dizem para sair, eu mostro isso a eles [o GFA]. Quando os trabalhadores têm medo de se juntar, mostro isso a eles. Quando as pessoas me dizem que não tem direito, aponto para isso".

Embora a África do Sul seja muito ampla para que se reivindique um efeito transformador a nível nacional, comparado com a organização dos trabalhadores da Firestone na Libéria ou da vitória da Russel em Honduras, os efeitos nacionais desta campanha global ilustram como a mobilização global pode contribuir para a revitalização do sindicato a nível nacional, mesmo em países maiores do Sul Global.

A Índia provou ser um terreno áspero para a construção de alianças transnacionais. A colcha de retalhos das confederações sindicais politicamente divididas da Índia fez da construção de uma campanha nacional unificada um desafio tão grande quanto aquele de construir uma campanha de escopo continental na África ou na América Latina. Os militantes do UNI na Índia tentando construir uma aliança entre o Congress of Indian Trade Unions (CITU), com grande participação do Partido Comunista, predominantemente marxista, em Bengal West e o ㄱ. Congress afiliado Indian Trade Union Congress (INTUC) no Sul da Índia. Problemas e conflitos \& em última instância, a Indian Security Workers 今 Organizaing Initiative (ISWOI), organizado

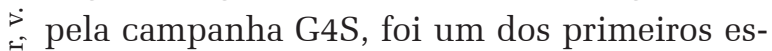
forços do tipo para ligar o fosso que separava a CITU e a INTUC. Segundo, numa amostra do poder do contexto político local, a campanha na Índia desenvolveu sua própria estratégia específica, consistente com as estratégias de outras campanhas bastante distintas de organi- zação na Índia, como a SEWA (Self-Employed Women's Association) (Agarwala, 2013). Em vez de demandar da companhia diretamente, a campanha terminou trabalhando por "uma legislação nacional que pudesse estabelecer padrões para os guardas de segurança em toda a indústria, estendendo efetivamente aspectos do acordo global à arena política indiana" (McCallum, 2013, p. 138).

A relação recíproca entre a mobilização nacional e global é clara na campanha G4S: os terrenos nacionais moldam o caráter e a efetividade das campanhas globais, mas as campanhas globais podem moldar, também, os contornos do terreno nacional. A campanha sublinha, uma vez mais, a importância da estratégia do Sul Global. Sem as mobilizações multinacionais por uma série de países no Sul Global e a evidência convincente dos salários e condições de trabalho degradadas que estes movimentos trouxeram aos escritórios dos representantes em Londres, é improvável que o empresariado global tivesse cedido. Finalmente, a campanha G4S traz à tona, uma vez mais, a mistura que vimos no Brasil: a utilização ao estilo europeu das estruturas sindicais Globais e de acordos de escopo também global, combinados com um estilo agressivo, de confronto, da campanha corporativa americana.

\section{CONEXÕES TRANSNACIONAIS E MOVIMENTOS DE TRABALHADO- RES NA ERA NEOLIBERAL}

A ideia de que novos tipos de transnacionalismo do movimento de trabalhadores emergiram na era neoliberal não é uma quimera. O neoliberalismo não impediu a emergência de novas conexões entre as forças sociais do trabalho nacionais. Uma fonte das novas possibilidades foi a mudança de posições dos terrenos nacionais na economia política global. Outra foi a construção de novas estratégias e estruturas a nível global. Tendo explorado estas possibilidades com algum detalhe, é hora 
de considerar suas implicações atuais e futuras para o movimento global de trabalhadores.

Foquei, particularmente, em como os deslocamentos das posições nacionais resultaram num crescimento da participação nas alianças transnacionais em dois países: o declínio dos Estados Unidos e um Brasil emergente. Mas as ramificações deste deslocamento vão além das estratégias cambiantes destes dois movimentos nacionais de trabalhadores. Elas envolvem uma ordem caleidoscópica de casos, envolvendo uma série de países tanto do Norte quanto do Sul.

No caso dos Estados Unidos, as duradouras políticas antitrabalhistas geraram novos incentivos para que os sindicatos olhassem para as alianças transnacionais. Embora parcial, este deslocamento criou oportunidades para outros movimentos nacionais. As vitórias da Honduran textile workers sobre a Russell athletics e a Liberian Plantatio Workers sobre a BridgestoneFirestone mostram a utilidade da abertura do movimento dos trabalhadores estadunidense para as iniciativas transnacionais, ao menos no caso de países pequenos e pobres, onde o capital local é dependente da economia dos Estados Unidos. O investimento organizacional da SEIU na campanha G4S ilustra como uma orientação mais transnacional nos Estados Unidos pode contribuir para campanhas mais amplas. A despeito do declínio de seus recursos ao nível nacional, o movimento americano de trabalhadores ainda detém poder e recurso suficiente para ser um útil aliado para outros movimentos.

O movimento de trabalhadores brasileiro aprendeu cedo o valor das alianças transnacionais, durante suas lutas contra o regime militar. A globalização do capital sediado no Brasil somou-se aos incentivos criados pela predominância continuada das corporações transnacionais, tornando o movimento de trabalhadores brasileiro ainda mais aberto às conexões com outros movimentos nacionais. A abertura para as estratégias transnacionais, combinada com capacidades políticas e organizacionais construídas por décadas de lutas, fez do movimento dos trabalhadores brasileiro um aliado valioso. Isto ficou particularmente claro no caso do apoio da Gerdau Workers World Council ao USW no caso Ameristeel, e também se aplica aos efeitos potenciais do apoio brasileiro à campanha da UAW Nissan, no Mississippi. Mas o papel do Brasil nas redes Sul-Sul - incluindo o GWWC e o REDLAT (Latin American Network for research on Multinational Companies) - também é importante. Juntos, estes casos corroboram uma visão expandida a respeito das possibilidades de chantagens patronais ao revés. Os exemplos tradicionais de chantagem patronal ao revés são: o movimento nacional de trabalhadores no Sul ganha poder construindo laços com o do Norte; tanto os sindicatos brasileiros quanto os sindicatos estadunidenses ganham poder construindo conexões com sindicatos mais solidamente institucionalizados na Europa. Porém, os casos Brasil-Estados Unidos mostram um tipo de chantagem patronal ao revés no qual a força do Sul pode resultar em benefício para o Norte.

Ao mesmo tempo, estes casos esclarecem a interação das campanhas globais e contextos políticos nacionais historicamente enraizados. Os contextos políticos nacionais continuam o maior determinante da sorte dos movimentos. Eles não são somente "variáveis independentes" que moldam possibilidades de ação transnacional. Eles podem ser, também, remodelados em prol do movimento dos trabalhadores por campanhas globais. Os esforços transnacionais podem catalisar vitórias e revigorar as forças sociais do trabalho no nível nacional - notadamente em países menores, como mostra Honduras e Libéria, e a um nível setorial mais específico em países maiores, como mostra o efeito revitalizador da campanha do G4S sobre o SATAWU. O Brasil mostra como um terreno favorável pode tanto estimular as articulações das redes transnacionais de trabalhadores quanto se beneficiar delas.

O desenvolvimento de novas conexões entre movimentos globais de trabalhadores na era neoliberal foi complementado pela construção de 
novas estratégias e estruturas a nível global. A estratégia de construção de instituições como o IFA/ GFA, conselhos de fábrica pelo mundo e redes empresariais cresceu rapidamente. Campanhas organizadas por vários países, que estão no centro da questão, não podem reivindicar o mesmo crescimento acelerado, mas a campanha G4S ilustra o acúmulo de experiência em como organizar mobilizações entre vários países. O movimento global dos trabalhadores continua "aprendendo na prática” a nível global, no neoliberalismo. Os sindicatos brasileiros estavam profundamente engajados com os modelos europeus de organizar, vinculados aos GFAs e aos Sindicatos Globais, mas estiveram igualmente abertos ao estilo americano de fazer campanhas nos casos da Gerdau e da Nissan. A campanha da G4S foi um híbrido que juntou os dois modelos.

Em termos gerais, a erosão do poder do trabalhismo movimento dos trabalhadores no nível nacional em muitos países cobrou seu preço, mas o desenvolvimento de estratégias e conexões globais continua. ${ }^{22} \mathrm{~A}$ evolução da arquitetura global não foi definida pela simples soma das conjunturas de suas partes nacionais. Novas conexões nacionais e aprendizagem prática global produziram resultados concretos para os trabalhadores em muitos países. O pulular constante de novos exemplos de transnacionalismo das 을 forças sociais do trabalho sob a égide do regime సั. neoliberal hostil pode não acarretar uma "grande Ф் transformação" do movimento dos trabalhadores ¿̊. ao nível global (Munck, 2002), mas, tampouco $\infty$ autorizam um "pessimismo teimoso" (Burawoy, 2010). Temperado cuidadosamente, o otimismo cético é sempre uma resposta razoável às ambiș guidades da evidência.

a $\quad$ E as implicações para o futuro? Os exem$\stackrel{\infty}{\sim}$ plos de transnacionalismo aqui considerados $\vec{r}$ representam um ponto evanescente criado por conjunturas idiossincráticas no período neoliberal? Ou, estas iniciativas provavelmente se

${ }^{22} \mathrm{Um}$ dos desenvolvimentos mais interessantes, cuja dis$\supsetneq$ cussão tive de deixar de lado aqui, envolve os laços entre

trabalhismo e outros movimentos sociais transnacionais

(ver, por exemplo, Anner e Evans, 2004; Tarrow, 2005; Evans, 2008; Munck, 2010; Smith e Wiest, 2012). tornarão características marcantes da contestação das forças sociais do trabalho ao capital nas décadas que virão?

As circunstâncias que produziram as inúmeras campanhas descritas aqui são pouco idiossincráticas. Decorrem da interação entre terrenos nacionais que são integrantes da estrutura geral da economia política global. Ao mesmo tempo, estas conexões transnacionais não fluem, simplesmente, das posições nacionais na estrutura da economia política global. Elas dependem, especificamente, de histórias nacionais. A sustentação e o reforço das estruturas e estratégias que emergiram a nível global dependem do apoio e do engajamento dos movimentos de trabalhadores ao nível nacionais e, por isso, são igualmente dependentes de um agregado de trajetórias políticas nacionais.

Os efeitos projetados do "Sul insurgente" fornecem uma boa ilustração da importância das trajetórias nacionais específicas. Por um lado, há boas razões estruturais para esperar que o Sul continue a tornar-se mais importante para o transnacionalismo do movimento dos trabalhadores. O Brasil ilustra como uma conjuntura nacional favorável pode ampliar um efeito geral. Porém, mesmo no caso do Brasil, não se pode assumir que o futuro será uma extensão das tendências passadas. Os analistas pessimistas argumentariam que o atual papel internacional do movimento de trabalhadores brasileiro representa um apogeu que dificilmente se sustentará, seja porque a CUT perdeu sua visão militante, que foi fundamental tanto para a política doméstica quanto para seu internacionalismo (Sluyter-Beltrao, 2010), seja porque o movimento dos trabalhadores brasileiros como um todo está preso a uma armadilha corporativista que minará a vontade para investir energia em campanhas combativas, sejam nacionais ou globais (Braga, 2012).

Considerando a evolução dos movimentos dos trabalhadores em outros grandes países do Sul Global, cujas trajetórias políticas pareciam igualmente promissoras nos anos 1980, mas que terminaram por não cumprir um pa- 
pel como o do Brasil, destaca-se ainda mais a importância das trajetórias políticas nacionais. A África do Sul é um caso concreto. ${ }^{23}$ A despeito dos apelos contínuos a um papel político mais ativo pelas bases dentro da COSATU (Congress of South African Trade Unions) (ver, por exemplo, Sikwebu, 2013), as forças sociais do trabalho, na prática, foram relegadas a ser um parceiro Junior numa aliança política cuja agenda diverge grandemente das prioridades das fileiras e do histórico da COSATU.

Em suma, a habilidade dos grandes movimentos de trabalhadores no Sul para trazer contribuições chave para a arquitetura geral das forças sociais do trabalho global é uma possibilidade que depende das trajetórias políticas nacionais. É possível que os deslocamentos políticos futuros em outros países do Sul Global - em algum lugar da África do Sul à Coréia - expandam possibilidades de construir articulações transnacionais. Mas, também é possível que o movimento de trabalhadores brasileiros se torne mais dividido e menos engajado transnacionalmente. A evolução futura da economia política provavelmente apresentará aos movimentos de trabalhadores do Sul Global oportunidades de cumprir um papel mais amplo no transnacionalismo, mas a possibilidade de captação destas oportunidades dependerá das trajetórias políticas nacionais. O movimento dos trabalhadores pode cumprir um papel na modelagem destas trajetórias não em sua determinação.

Um ponto similar pode ser assinalado com relação ao deslocamento em direção ao transnacionalismo no movimento de trabalhadores estadunidense. Argumentei que o declínio neoliberal dos Estados Unidos teve o efeito de pressionar as forças sociais do trabalho estadunidense em direção ao transnacionalismo, mas, insisto, os efeitos do declínio da hegemonia não devem ser tomados genericamente. Os movimentos dos trabalhadores europeus possuem um recorde melhor que os sindicatos

${ }^{23}$ Sobre paralelos entre as fases anteriores da luta dos trabalhadores no Brasil e na África do Sul, ver Seidman (1994). estadunidenses para contribuir para os esforços transnacionais durante a fase ascensional da hegemonia americana. Como os exemplos dos esforços de solidariedade alemã na indústria automobilística tanto no Brasil quanto nos Estados Unidos ilustram, esta tradição continua. O declínio do movimento dos trabalhadores europeu durante o século XXI não parece haver estimulado um deslocamento na direção de um aumento do transnacionalismo, comparável com aquele que argumentei ter ocorrido nos Estados Unidos. Em suma, não podemos sustentar que o declínio econômico e os ambientes políticos nacionais mais hostis às forças sociais do trabalho empurrarão o movimento dos trabalhadores no Norte para fora.

Tampouco é linear a conexão entre declínio da hegemonia e crescimento do transnacionalismo do movimento dos trabalhadores nos Estados Unidos. Um declínio acelerado poderia minar a capacidade do movimento dos trabalhadores estadunidense para ser um aliado útil. Isso deveria provocar um giro interno, particularmente se os esforços transnacionais atuais não geram frutos aos trabalhadores estadunidenses.

A maior fonte de incerteza com respeito ao futuro do transnacionalismo do movimento dos trabalhadores não vem, claro, dos Estados Unidos, mas do outro lado da equação da hegemonia em transformação. Se a hegemonia emergente da China resultar na expansão global da repressão bastante efetiva das organizações trabalhistas independentes por parte do Partido -Estado, as perspectivas para o movimento dos trabalhadores ao nível global seriam cinzentas. Neste cenário distópico, o regime neoliberal hostil poderia aparecer, retrospectivamente, como não sendo o apogeu da política antitrabalho, mas como sendo a última "janela de oportunidade" para as forças sociais do trabalho.

Não há garantias de que as conexões nacionais desenvolvidas no neoliberalismo não sejam desgastadas ou revertidas pela mudança política nas arenas nacionais ou deslocamentos na hierarquia do poder nacional que estruturam a economia política global, mas a con- 
tinuidade de um conjunto de oportunidades basicamente semelhantes àquelas oferecidas pela era neoliberal é uma projeção razoável. Deste modo, faz sentido focar na lição que podemos aprender das experiências das décadas recentes sobre as dinâmicas que moldam a arquitetura global das forças sociais do trabalho.

A inabilidade para fornecer predições claras acerca das trajetórias futuras não anula o interesse na reflexão sobre as articulações entre os movimentos dos trabalhadores em níveis nacionais nos últimos vinte anos como meio de entender a evolução da arquitetura das forças sociais do trabalho em nível global. A incerteza a respeito das tendências do futuro tampouco deveria distrair das implicações de se focar nas conexões dos movimentos nacionais de trabalhadores para as análises estratégicas empregadas nos estudos globais sobre o trabalho.

As teorias pessimistas sobre o padecimento do trabalho nas mãos no neoliberalismo devem ser reconciliadas com as teorias otimistas do novo transnacionalismo neste campo. Integrar a análise de interações entre o movimento de trabalhadores nacional com as análises tanto do que está ocorrendo nos terrenos nacionais quanto ao nível global é uma forma de fazê-lo. Uma teoria do movimento dos trabalhadores global excessivamente ancorada no ᄂ2 nível global será sempre parcial e equívoca. A స్ atenção dada à construção de blocos nacionais Ф் tampouco deveria ser limitada à descrição das maneiras pelas quais as diferenças nacionais $\infty$ podem subverter a solidariedade transnacional. † O potencial para as sinergias positivas, criadas pela diferença nacional, merece igual atenção. is Investigar a variedade de maneiras pelas quais \& os movimentos de trabalhadores nacionais po-

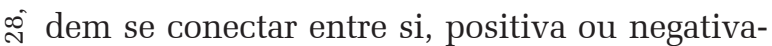
$>$ mente, é uma fundação necessária para melhores teorias da evolução da contestação das forças sociais do trabalho ao capital global.

Recebido para publicação em 26 de maio de 2015 Aceito em 10 de agosto de 2015

\section{REFERÊNCIAS}

AGARWALA, R. Informal labor, formal politics, and dignified discontent in India. Cambridge: Cambridge University Press. 2013.

ANNER, M. Industrial structure, the state, and ideology: Shaping labor transnationalism in the Brazilian auto industry. Social Science History. v. 27, n. 4, p. 603-634, 2003.

Solidarity transformed: labor responses to globalization and crisis in Latin America. Ithaca: Cornell University-ILR Press. 2011.

Workers power in global value chains: fighting sweatshop practices at Russell, Nike and Knights Apparel. In: FAIRBROTHER, P.; HENNEBERT, M.A.; LEVESQUE, C. (eds.). Transnational trade unionism building union power. New York: Routledge. 2013.

EVANS, P. Building bridges across a double-divide: alliances between U.S. and Latin American labor and NGOs. Development in Practice. v. 14, n. 1-2, p. 34-47, 2004.

ARRIGHI, G. The three hegemonies of historical capitalism. Review. XIII, v. 3, p. 365-408. 1990.

The long Twentieth Century. Money, power, and the origins of our times. London: Verso. 1994.

Workers of the world at century's end. Review. $\overline{X I X, v .3}$, p. 335-351, 1996.

. Adam Smith in Beijing: Lineages of the TwentyFirst Century. London: Verso. 2007. Aschoff, N. (2014) 'Tennessee Car Sick Blues', Jacobin. February, [Online]. Available at https://www.jacobinmag.com/2014/02/ tennessee-car-sick-blues/, [Accessed: 9 June 2014]. Automotive News. (2013) 'VW labor chief says Chattanooga model hinges on works panel,' (October 7), [Online]. Available at www.autonews.com/article/20131007/ OEM01/ 131009897, [Accessed: 9 June 2014].

BRAGA, R. A política do precariado: do populismo à hegemonia lulista. São Paulo: Boitempo. 2012.

BRONFENBRENNER, K. (ed.) Global unions: challenging transnational capital through cross-border campaigns. Ithaca: Cornell University-ILR Press. 2007.

BURAWOY, M. From Polanyi to Pollyanna: the false optimism of global labor studies. Global Labour Journal. v. 1, n. 2, p. 301-313, 2010.

CHIBBER, V. Into the fold: labor's incorporation into the Indian Political Economy. In: GOLDFIELD, Michael; BANERJEE, Debdas (eds.). Labour, globalization, and the state. London: Routledge. 278, 2007.

COMPA, L. (in collaboration with the NAACP Mississippi State Conference). (2013) 'Choosing Rights: Nissan in Canton, Mississippi, and Workers' Freedom of Association under International Human Rights Standards', [Online]. Available at http://dobetternissan.org/ 2013/10/compareport, [Accessed: 9 June 2014].

DAVIS, B. The struggle of the national mine, metal and steel workers union of the Mexican Republic. In: Toledo, E.G. (ed.) La situación del trabajo en México: el trabajo en la crisis. Madrid, Spain: Plaza y Valdes. 2012.

DONIZETTI, P. Sonhos violados, Rede Brazil. [Online]. Available at www.redebrasilatual.com. br/revistas/81/ trabalho/, [Accessed: 23 July 2013]. 2013.

EARLY, S. VW to UAW: so long partner? CounterPunch. (February 19), [Online]. Available at http://www. counterpunch.org/2014/02/19/vw-to-uaw-so-longpartner/, [Accessed: 9 June 2014]. 2014

EVANS, P.B. Is an alternative globalization possible? Politics \& Society. v. 36, n. 2, p. 271-305, 2008.

Is it labor's turn to globalize? Twenty-First 
Century opportunities and strategic responses. Global Labour Journal. v. 1, n. 3, p. 352-379, 2010.

; SEWELL, W.H. 'Neoliberalism: Policy regimes, international regimes, and social effects. In: HALL, P; LAMONT, M. (eds.) Social resilience in the neoliberal era. Cambridge: Cambridge University Press. 2013.

FICHTER, M.; HELFEN, M. Going local with global policies: implementing international framework agreements in Brazil and the United States. In: PAPADAKIS, K. (ed.) Shaping global industrial relations: the impact of international framework agreements. New York: Palgrave Macmillan. 2011.

GRAHAM, A. Massive victory for Honduran workers. Against the Current. v. 24, n. 3, p. 21-22. 2010. Gray, C. Metalúrgicos sem fronteiras: Building a global union at Gerdau. Unpublished MA Thesis, Cornell University. 2009.

GREENHOUSE, S. Labor fight ends in win for students. The New York Times. November, 18. 2009.

At a Nissan Plant in Mississippi, a Battle to Shape the U.A.W.'s Future,' The New York Times. [Online]. 2013. Availableat http://www.nytimes.com/2013/10/07/business/ at-a-nissan-plant-in-mississippi-a-battle-to-shape-theuaws-future.html, [Accessed: 9 June 2014]. Hermanson, J. (2004) 'Global corporations, global campaigns: The struggle for justice at Kukdong International in Mexico' Paper presented at Cornell University Conference on Transnational Labor Contention, April 9-11, 2004. 279

INTERNATIONAL LABOR RIGHTS FORUM (ILRF). Liberia: Firestone Sued Over 'Slave' Plantation. International Labor Rights Forum. [Online]. Available at http://www.laborrights.org, [Accessed: 4 December 2005].

IMF (INTERNATIONAL METALWORKERS FEDERATION) (2012) 'International framework agreement: Agreed upon social rights and social responsibility principles', Ford Motor Company and Global IMF I. Ford Global Information Sharing Network, April 25, 2012.

JAKOBSEN, K. Rethinking the International Confederation of free trade unions and its Inter-American regional organization. Antipode. v. 33, n. 3, p. 363-383, 2001.

Estratégia sindical frente às empresas multinacionais. Nueva Sociedad, 211 Sep./Oct., p. 145-159. 2007.

JURAVICH, T.; BRONFENBRENNER, K. Ravenswood: the steelworkers victory and the revival of American labor. Ithaca: Cornell University-ILR Press. 1999.

KAY, T. NAFTA and the politics of labor transnationalism. Cambridge: Cambridge University Press. 2010.

KAZDIN, C. What lessons from the USW's Transnational Solidarity Campaigns? Presentation at workshop on 'New Strategies For Building Transnational Labor Solidarity' November 8th Watson Institute, Brown University, Providence RI. 2012

LULA [LUIZ INÁCIO DA SILVA]. Letter to NISSAN (October, 10), [Online]. 2013. Available at http://dobetternissan. org/2013/10/former-brazil-president-lulas-letter-to-nissan, [Accessed: 9 June 2014]

MSN (MAQUILA SOLIDARITY NETWORK) Evangelina Argueta of the Maquila Solidarity Network speaks about her life as a union organizer, [Online]. 2010. Available at http://en.maquilasolidarity. org/node/964, [Accessed: 23 July 2013].

MAZUR, J. Labour's New Internationalism. Foreign Affairs. v. 79. n. 1, p. 79-93. 2000. McCallum, J. 'Trade union renewal and labor transnationalism in South Africa: The case of SATAWU', WorkingUSA: The Journal of Labor and Society. v. 14, June, p. 161-176, 2011.

MCCALLUM, J. Global unions, local power: the new spirit of transnational labor organizing. Ithaca: Cornel University Press. 2013.
MUNCK, R. Globalization and labour: the new 'Great Transformation’. London: ZED Books. 2002.

Globalization and the labour movement: challenges and responses. Global Labour Journal. v.1, n. 2, p. 218-232, 2010.

MYERSON, H. Where are the workers? The American Prospect. v. 20, n. 2, p. 20. 280, 2009.

RODRIGUEZ-GARAVITO, C.A. Sewing resistance: transnational organizing, global governance, and labor rights in the U.S.-Caribbean Basin apparel industry (19902005). Unpublished Ph.D. Dissertation, Department of Sociology, University of Wisconsin, Madison, WI. 2007.

ROMBALDI, M. Internacionalizacão do sindicalismo no Brasil: um estudo sobre os setores metalúrgico e de telecomunicações. Tese de Doutorado, Departamento de Sociologia, Universidade de São Paulo, São Paulo, Brazil. 2012.

RÜB, S. World works councils and other forms of global employee representation in transnational undertakings. Working Paper 55. Dusseldorf: Hans-Böckler-Stiftung. 2002 .

SCIPES, K. AFL-CIO's secret war against developing country workers: solidarity or sabotage? Lanham, MD: Lexington Books. 2010.

SEIDMAN, G. Manufacturing militance: workers' movements in Brazil and South Africa, 1970-1985. Berkeley, CA: University of California Press. 1994.

Beyond the boycott: labor rights, human rights, and transnational activism. New York: Russell Sage Foundation. 2007.

SIKWEBU, D. Notes from a Trade Unionist: Cosatu and its Affiliates as Democratising Agents or Contingent Democrats?' Rethinking Development and Inequality. v. 2, p. 63-67, 2013)

SILVER, B.J. Forces of labor: workers' movements and globalization since 1870. Cambridge: Cambridge University Press. 2003.

SLUYTER-BELTRÃO, J. Rise and decline of Brazil's new unionism: the politics of the Central Unica dos Trabalhadores. Oxford: Oxford University Press. .2010.

SMITH, J.; WIEST, D. Social movements in the worldsystem: the politics of crisis and transformation. New York: Russell Sage Foundation. 2012. Standing, G. The precariat: the new dangerous class. London: Bloomsbury Academic. 2011

STEVIS, D.; BOSWELL, T. International framework agreements: opportunities and challenges for global unionism. In: BRONFENBRENNER, K. (ed.) Global unions: challenging transnational capital through cross-border campaigns. Ithaca: Cornell University-ILR Press. 2007.

Globalization and labor: democratizing global governance. Plymouth: Rowman and Littlefield Publishing. 2008.

TARROW, S. The new transnational activism. New York: Cambridge University Press. 2005.

UNDP (UNITED NATIONS DEVELOPMENT PROGRAM). Human development report: the rise of the South. New York: UN. 281. 2013

VEIGA, J.P.C.; JAKOBSEN, K. A cooperação laranja verde amarela: A parceiria FNV e CUT. São Paulo, Brazil: CEDOC-CUT. 2011.

WATERMAN, P. Trade Union Internationalism in the Age of Seattle. Antipode. v. 33, n. 3, p. 312-336, 2001.

WEBSTER, E., LAMBERT, R.;BEZUIDENHOUT. A. Grounding globalization: labor in the age of insecurity. Malden: Blackwell. 2008 


\section{NATIONAL WORKER'S MOVEMENTS AND TRANSNATIONAL CONNECTIONS: evolution of the architecture of work forces in neoliberalism}

Peter Evans

The neoliberal era has undermined worker's rights and labor's power at the national level, but has also been characterized as an era of "the new labor transnationalism”. Shifting fortunes at the national level have been fundamental to expanding openness to transnational alliances. An analysis of campaigns displays that. Assessing the connections among national labor movements and the new global organizational infrastructure that have emerged under neoliberalism is a necessary foundation for building better theories of labor's evolving contestation with global capital.

KEY-WoRDS: Workers. Global Unions. Labor transnationalism. Labor national movements. Neoliberalism.

\author{
MOUVEMENTS NATIONAUX DES \\ TRAVAILLEURS ET LIAISONS \\ TRANSNATIONALES: l'évolution de la \\ construction des forces sociales du travail au sein \\ du néolibéralisme
}

Peter Evans

L'ère néolibérale a miné les droits des travailleurs et le pouvoir des forces sociales du travail au niveau national mais a aussi été caractérisée comme l'ère d'un nouveau "transnationalisme du mouvement des travailleurs". Les changements conjoncturels au niveau national ont joué un rôle fondamental pour amplifier l'ouverture à des alliances transnationales. Une analyse des campagnes permet de le mettre en évidence. Faire l'évaluation des liens existants entre les mouvements nationaux des travailleurs et la nouvelle infrastructure organisationnelle qui a surgi au sein du néolibéralisme est un point de départ nécessaire à la construction de théories plus précises concernant les dynamiques de contestation des forces sociales du travail envers le capital mondial.

Mots-CLÉs: Travailleurs. Syndicats mondiaux. Transnationalisme. Syndicats nationaux. Néolibéralisme.

Peter Evans - Professor emérito de Sociologia da University of California, Berkeley e Senior Research Fellow da Watson Institute for International Studies da Brown University. Também trabalha como coordenador do Grupo e Trabalho sobre Movimentos de Trabalhadores da Associação Internacional de Sociologia (ISA). Seu trabalho anterior centrava-se na economia política do desenvolvimento comparado no Sul global. Recentemente vem pesquisando os esforços dos movimentos sociais para mobilizar transnacionalmente uma "globalização contra-hegemônica". O movimento global dos trabalhadores é um foco central em seu trabalho, como exemplifica o artigo aqui publicado e seu texto de 2010 editado no Global Labour Journal 'Is it Labor’s Turn to Globalize?' 